\title{
A JUDICIALIZAÇÃO DA INFÂNCIA: Concepções em torno do trabalho infantil no Código de Menores de 1927
}

\author{
CHILDHOOD JUDICLALIZATION: Conceptions about cbild labor in the Code of Minors of 1927
}

\author{
Sônia Camara ${ }^{1}$ \\ Dante Batista Silva ${ }^{2}$
}

http://dx.doi.org/10.52641/cadcaj.v6i4.529

\begin{abstract}
RESUMO: Este artigo objetiva problematizar o processo de judicialização da infância a partir da promulgação do Código de Menores de 1927, no que tange à proteção da infância, discutindo algumas concepções em torno do trabalho infantil que se materializaram na lei. Com esse intento, tencionam por um lado, demonstrar, por meio de casos veiculados em jornais, os abusos de exploração do trabalho infantil e, por outro, indiciar as medidas previstas no Código para prevenir e ou regulá-lo. Destaca-se a importância da referida legislação no tocante à regulamentação do trabalho do menor no período histórico, analisando, para isso, um vasto repertório documental constituído por legislação, periódicos e livros. Em sua formulação, o Código de Menores visava regular o trabalho infantil de modo a resguardar a vida das crianças para o bem da pátria. Para isso, propugnava por uma educação voltada para o trabalho a partir das instituições disciplinares destinadas a preservar e regenerar a infância identificada como abandonada e delinquente.
\end{abstract}

Palavras-chaves: História da Educação. Judicialização da infância. Código de Menores.

\begin{abstract}
The article aims to problematize the judicialization of childhood from the promulgation of the Code of Minors of 1927, with regard to the protection of childhood, problematizing conceptions of child labor materialized in the law. With this intention, it intends to demonstrate, through cases published in newspapers, the abuses of exploitation of child labor and, on the other hand, to indicate the measures foreseen in the Code to prevent and regulate. The importance of the legislation in terms of the reality of the child's labor in the historical period is highlighted, analyzing for that purpose a vast documentary repertoire applicable by legislation, periodicals and books. In its formulation, the Code of Minors aimed to regulate child labor in order to safeguard the lives of children for the improvement of the country. To that end, it used efforts in favor of work-oriented education from disciplinary institutions aimed at preserving and regenerating a childhood identified as abandoned and delinquent.
\end{abstract}

Keywords: History of Education. Judicialization of childhood. Minors Code.

\footnotetext{
${ }_{1}^{1}$ Professora Associada da Universidade do Estado do Rio de Janeiro, atuando no Programa de Pós-Graduação em Educação da Faculdade de Educação (Proped) e do Programa de Pós-Graduação Processos Formativos e Desigualdades Sociais da Faculdade de Formação de Professores. Lider do Grupo de pesquisa Núcleo Interdisciplinar de Pesquisa em História da Educação e Infância (NIPHEI) e Procientista da UERJ. E-mail: soniacamara@uol.com.br. 2 É bacharel em Direito, Especialista em Direito Empresarial pela Universidade Metodista de Piracicaba - UNIMEP. Mestre em Educação pela Universidade São Francisco - USF. Doutorando em Educação na Universidade do Estado do Rio de Janeiro - UERJ. Bolsista PROEX-CAPES (2021). Membro do Grupo de Pesquisa TCTCLAE - Teoria Crítica e Teorias Críticas Latino-Americanas e Educação. Membro do Grupo de Pesquisa em História da Educação e Infância (NIPHEI). E-mail: batista.dante@gmail.com.
} 


\section{INTRODUÇÃO}

Sem ar, sem alimentação, Helena sacrificando os seus olhos e a sua saúde, trabalhava noite e dia, a agulha entre os dedos, como tantas costureirinhas, como milhares de outras costureirinhas, para a fortuna da elegante casa da Avenida e para enriquecer o generoso turco das prestações...

Com sacrifício da mocidade e da existência da pequena Helena, o mundo não deixava por isso, de rodar, sobre si mesmo, todos os dias...

Mas como uma flor que murchasse, a pequena operária ia empalidecendo, pouco a pouco, e ao redor dos seus olhos, grandes e largas manchas arroxeadas iam se formando. Magra, muito magra, muito anêmica, Helena tinha aspecto de velhice precoce, essa velhice que as próprias crianças miseráveis e mal alimentadas têm...

Era uma velha antes de ter sido uma moça! (CONSTALLAR, 1995, p. 66).

A emergência do problema da infância, a partir de finais do século XIX e início do XX, passou a compor, entre outros temas candentes à época, o arsenal de questões que mobilizou a atuação dos reformadores sociais, - médicos, escritores, advogados -, envolvidos em pensar a sociedade e, em particular a situação das crianças vistas como vítima das ausências e dos excessos. Se, por um lado, as ausências se materializavam na falta de escola, de educação e de ações protetivas por parte do Estado; por outro lado, os excessos se corporificavam no abandono, na criminalização precoce, no alto índice de mortalidade, no analfabetismo e na exploração compulsória do trabalho a que estavam submetidas as crianças, especialmente, nos grandes centros urbanos onde a realidade social plasmava um quadro de desamparo e abandono.

Nas páginas dos jornais cariocas eram frequentes os casos envolvendo maus tratos, violência e exploração de crianças. Exemplar nesta direção é a crônica intitulada $A$ pequena operária, publicada no Jornal do Brasil ${ }^{3}$ por Benjamim Constallat (1995). No texto o jornalista "denunciava" nas páginas do jornal a realidade social das crianças, corporificada na história de Helena, pequena costureirinha que, como tantas outras meninas pobres, trabalhavam como operária para sobreviver. Em sua narrativa, a crônica expõe aspectos de uma realidade subterrânea que a partir dos finais do século XIX, assumiu ares de problema social. Nesse contexto, observa-se uma crescente sensibilização por parte de diferentes setores da sociedade com relação à situação da infância. Esta sensibilização indicia uma mudança de mentalidade assente na ideia de que o novo século via

\footnotetext{
${ }^{3}$ No artigo trabalhamos com os escritos do jornalista publicados no livro Mistérios do Rio, publicado pela Secretaria Municipal de Cultura do Rio de Janeiro, em 1995.
} 
eclodir a ideia de que era imperioso denunciar, mas também agenciar ações intervencionistas sobre a realidade social do país.

Embora situações envolvendo abandono, delinquência e violência contra crianças fizessem parte da cena urbana das cidades, desde o período colonial, com a proclamação da República, em 1889, a questão recebeu um tratamento diferenciado, mobilizada pelo desejo de se instaurar a modernização e o progresso do país. Embebidos por esse ideal de transformação, projetos foram arquitetados, por setores da intelectualidade, tencionando modificar o panorama social, político e econômico que se descortinava como inóspito, desregrado e atrasado. Como afiança Botelho (2002, p. 33) o tema da ilustração no atraso passava pelo ideal de que era preciso formar os "portadores sociais da cultura política moderna" como condição para a constituição da nação. Esse ideal reformador da sociedade passava indubitavelmente pela educação, meio capaz de promover a difusão de "valores e regras normativas" da sociedade. De tal modo que:

Instituir uma estrutura teórica capaz de normalizar, moralizar, educar e higienizar a sociedade, concebendo-a como um corpo que deveria ser, minuciosamente, conhecido, colocou-se como desafio para os intelectuais que pretenderam disseminar procedimentos técnico-científico adequados ao desenvolvimento sócio-cultural do país. Em nome da civilização, da ordem e do progresso expurgaram antigas concepções, propugnando o predomínio das ciências naturais, da biologia evolutiva e da antropologia física e determinista como suportes a afiançar o insofismável valor da ciência na configuração e na organização de instâncias de intervenção sobre o papel a ser desempenhado pela criança na sociedade brasileira de então (CAMARA, 2011, p. 19).

$\mathrm{Na}$ cidade do Rio de Janeiro, capital do país, a belle époque ${ }^{4}$ se afigurava como condição necessária para a construção e incorporação de uma vida elegante e própria às elites. O ideal de país que se descortinou dos escombros das demolições provocadas pelas reformas urbanísticas e sanitárias era avesso à desordem, à pobreza e à feiura. Entusiastas desse novo tempo, alguns jornais anunciavam o alvorecer de um novo dia, no qual: "temos ordem no progresso e as ordens prosperam. Dissiparam-se os fantasmas que assustavam a burguesia. Ninguém mais está preocupado com atentados ora que as companhias teatrais oferecem tantas tentações [...] O Brasil vaga sereno e galhardamente em mar de rosas [...]" (apud NEEDELL, 1993, p. 39). Se, por um lado, o entusiasmo caminhava evolutiva e progressivamente, a realidade, por outro lado, dava indícios do seu arrefecimento à mudança sendo preciso superar as contradições sociais que marcavam a cena urbana da capital do país.

\footnotetext{
${ }^{4}$ Segundo Costa e Schwarcz (2000), no Brasil e, em especial no Rio de Janeiro, a atmosfera que se desenhou a partir de 1890 até a Primeira Guerra Mundial (1914) era de otimismo, de certeza na prosperidade, de uma ideia ilimitada de confiança de que o país caminhava rumo ao progresso e a civilização, em um processo de "regeneração".
} 
As reformas empreendidas na cidade-capital não se limitaram à paisagem urbana, com a construção de ruas, de avenidas, de boulevard e o desmonte de morros e casarões, incidiram, também, sobre o cotidiano dos seus moradores prescrevendo normas e estabelecendo padrões sociais a serem seguidos. Se o cenário que se descortinava era favorável para as elites que viam plasmar uma nova cena carioca, para os setores pobres da sociedade a cena era de intervenção compulsória sobre sua forma de vida vistas como desregrada e imprópria. Desse modo, a cidade capital, eivada por mazelas sociais, envolvendo abandono e delinquência da infância contribuía, sobremaneira, para a urgência na elaboração de ações intervencionistas e assistenciais acionadas pelo crescimento da pobreza, da criminalidade e do medo. Nessa direção, afirma Mineiro (1929) que:

\footnotetext{
A importância vital desse magno problema, a necessidade urgente de resolvêlo, despertaram por toda parte o máximo interesse, que se vem desenvolvendo há cerca de três quartos de século, preocupando os sociólogos e os criminalistas, sendo objeto dos congressos de proteção à infância, dos penitenciários, dos de beneficência, os quais propuseram e votaram múltiplas e complexas soluções; e tem merecido em todos os países progressistas a decretação de leis especiais, a criação de iniciativas particulares fecundas, os cuidados de uma ação social sistemática, visando o nobre fim de amparar, preservar, educar e regenerar os menores abandonados e delinquentes, para os tornar membros úteis e honrados da sociedade (MINEIRO, 1929, p. 17 - grifos nossos).
}

No contexto internacional as questões relacionadas à infância assumiam centralidade e importância como problema a ser enfrentado pelas nações consideradas cultas e civilizadas. No Brasil, a questão foi pautada pela intelectualidade que, afinada com essa bandeira, fez ecoar projetos direcionados a promover sua assistência e proteção. Neste particular, ações visando constituir legislações especifíficas para à infância plasmaram-na. Mobilizadas pela atuação de intelectuais e políticos a partir de 1902, iniciativas foram organizadas objetivando compor a elaboração de um ordenamento jurídico destinado à infância no Brasil (CAMARA, 2010, p. 251). As propostas elaboradas por legisladores, a exemplo de Lopes Trovão, João Chaves e Alcindo Guanabara configuraram-se como tentativas efetivas em direção à composição de uma legislação destinada à infância. Embora relegadas ao arquivamento pelas comissões legislativas da Câmara e do Senado, as ideias que as organizaram no que tange à institucionalização, assistência e proteção à infância permaneceram municiando os debates e ações nos meios científicos e políticos das décadas de 1910 e 1920.

Para efeito deste artigo interessa refletir acerca das ideias jurídicas que se corporificaram no Código de Menores de 1927, no que se refere à compreensão do trabalho como instância capaz de contribuir para a regeneração, na preservação e na educação da infância. A partir desse tripé, objetiva-se analisar as acepções de trabalho que tomaram forma em sua redação, bem como as 
medidas propostas no sentido de se regular o trabalho da criança. Importa considerar que as ideias expressas em sua redação são compreendidas em confluência com os debates e proposições que estiveram em voga na década de 1920. Com esse intuito será acionado um repertório documental constituído por: jornais, legislação e livros de época que permitam perspectivar o Código de Menores em seu contexto de produção, concebendo-o como documento regulador das relações sociais. Assim, para efeito dessa análise, o artigo organiza-se em duas partes. Na primeira, intenta promover uma reflexão do Código em conexão com os movimentos e injunções do seu tempo. $\mathrm{Na}$ segunda, visa explorar as acepções de trabalho e os marcos reguladores instituídos no Código de Menores de 1927, em interface com alguns casos que repercutiram pela imprensa, na cidade do Rio de Janeiro, no que se refere às condições de exploração e violência a que estava submetida a infância trabalhadora.

\section{A CONSTRUÇÃO DA LEGITIMIDADE: O JUIZ, O CÓDIGO, AS INFÂNCIAS.}

Compreendendo a infância abandonada como "sementeira do crime" (MINEIRO, 1929, p. 17), setores da elite perspectivaram o futuro como possibilidade de se construir um destino glorioso ou infame para as crianças do país. O destino a ser traçado dependia, indubitavelmente, da atuação sistemática e esclarecida a ser realizada pelo Estado brasileiro. A partir da ideia de que era necessário intervir no "presente" das crianças, considerado lastimável e condenável, setores da intelectualidade defendiam a urgência em se estabelecerem ações destinadas a intervir na sociedade à luz da ciência.

A implementação de um movimento embrionário visando à composição do Código de Menores de 1927, e o convite formulado ao ex-deputado, professor, advogado e criminalista, José Cândido de Albuquerque Mello Mattos para subscrever uma proposta de substitutivo ao projeto que tramitara na Câmara dos Deputados, apresentado, anteriormente, por Alcindo Guanabara (1917), deve ser compreendidos em injunção com o contexto de sua elaboração. O projeto, de autoria de Mello Mattos foi submetido a uma comissão composta pelos professores Carvalho Mourão e Esmeraldino Bandeira, pelo desembargador Nabuco de Abreu, pelo Juiz Alfredo Russel, pelo Pretor Edgar Costa, pelos advogados Astholpho Rezende, Evaristo de Moraes e Baltazar da Silveira; pelo Médico Moncorvo Filho, pelo Deputado Federal Deodato Maia e pelo Diretor da Escola Quinze de Novembro, importante instituição de atendimento à infância da capital do país, Franco Vaz. Após um longo período de tramitação no Senado, com a adoção de emendas e revisões pela comissão, o substitutivo foi aprovado (MINEIRO, 1929, p. 20). 
Em sua formulação, o substitutivo previa a criação de instituições de internação e de aparatos legais no âmbito da proteção, da assistência e da regeneração do menor. O decreto número 16.272 de 20 de dezembro de $1923^{5}$, aprovava o regulamento da assistência e proteção aos menores abandonados e delinquentes, autorizando o governo a criar o Juízo de Direito Privativo de Menores ${ }^{6}$, o Abrigo para recolhimento dos "menores" e outros dispositivos complementares. Por intermédio desses aparatos, esse decreto instituiu um corpo de regras e procedimentos que, aplicados, constituíam-se nas primeiras ações em direção à afirmação de uma legislação geral de proteção à infância na cidade do Rio de Janeiro, então capital do país e, por conseguinte para todo o país. ${ }^{7}$

Com a materialização das medidas de assistência e proteção, a partir de $1925^{8}$, objetivou-se redimensionar o poder do Estado com relação às famílias, estabelecendo a prevalência do juiz na salvaguarda, especialmente das crianças da primeira idade. Nesse processo, ocorreu a mudança do eixo de ação do castigo identificado como forma de punir as crianças desviadas, abandonadas e criminosas, para a noção de preservação, cuidado e regeneração do menor. Novos critérios foram acionados a partir dos quais se concebeu a criação de instituições vocacionadas à preservação e à regeneração da infância. Quanto aos debates acerca do Código de Menores, pondera Mineiro (1924) que:

Chegou-se á conclusão de que a infância e adolescência devem ser postas fora
do Código Penal e do direito judiciário comuns; que é conveniente subtraí-las
às sanções penais cominadas(sic) aos adultos; que é oportuno, até urgente, criar
para eles um direito, no qual a educação substitua a punição, que, em vez do
regime penitenciário, seja adotado para eles um regime pedagógico e tutelar, o
qual, sem apresentar os inconvenientes da pena, os ponha fora das condições
de prejudicar, e, ao mesmo tempo, lhes dê o que lhes falta, isto é, a educação
moral, pois o de que eles mais necessitam, é que se lhes forme o caráter por
um sistema de vigilância, de proteção e disciplina apropriado. As medidas a eles
aplicadas têm por fim, em vez de castiga-los, reergue-los e preserva-los; não
punir, sim proteger (MINEIRO, 1924, p. 7).

${ }^{5} \mathrm{O}$ decreto foi organizado em duas partes: uma geral e outra especial. A segunda referia-se ao Distrito Federal (Rio de Janeiro). Na parte relativa ao Distrito Federal estrabelecia a criação do Juízo de Menores destinado a "[...] assistência, proteção, defesa, processo e julgamento de menores abandonados e delinquentes". O decreto estabelecia ainda a criação do Conselho de Assistência e Proteção aos Menores (BRASIL, Decreto 16.272, 1923).

${ }^{6}$ O Juízo foi pensado como instância capaz de instituir a proteção jurídica e social ao menor, constituindo-se como parte de um complexo tutelar de atendimento à infância. Como parte desse complexo foram fundadas instituições (institutos disciplinares), a Casa das Mãezinhas, A Casa Mello Mattos, O Recolhimento Infantil, entre outras.

${ }^{7}$ Para o aprofundamento desse debate, conferir o trabalho de Camara (2010).

${ }^{8}$ Pelo Decreto 4.793, de 1924 ratificaram-se os dois decretos anteriores, passando estes a adquirirem força legal. Ainda em 1924, foram sancionados os Decretos 16.388, que criou o Conselho de Assistência e Proteção aos Menores, como órgão complementar de assistência social, e o Decreto 16.444, que regulamentou o Abrigo Provisório de Menores. Todos os projetos apresentados a partir de 1921 estiveram sob a redação de Mello Mattos. (Carvalho, 1970, p.8). 
No contexto dos debates pela aprovação do Código de Menores, o crescimento dos índices de criminalidade, de abandono e de exploração a que estavam expostas as crianças, apareciam como elementos capazes de justificar a adoção das ações judiciais e tutelares por parte do Estado brasileiro, invocando noções novas que visavam estabelecer uma oposição entre punição e preservação e, assim evocar a ideia de proteção e disciplina como elementos essenciais à formação moral das crianças. Nesse contexto proliferaram discursos "aguerridos" em nome da cruzada protetora da infância.

Nessa perspectiva de análise, para Camara (2010, p. 260), o Código de Menores não deve ser compreendido "como produto, strito sensu, dos debates encampados pelo campo jurídico". A sua produção evidencia o predomínio desse campo de saber na direção do processo de composição das legislações, sem deixar de esboçar a confluência de propostas e intenções que estiveram inscritas e associadas aos movimentos empreendidos por médicos, educadores e outros setores da sociedade.

Concordamos com Camara (2010) quando afiança que o Código de Menores constituiu-se como documento síntese das ideias e lutas políticas e sociais que se realizaram no interior do campo jurídico e fora dele. As concepções professadas, ao assumirem estatuto de lei foram içadas ao status de legítimas e legais, configurando-se como expressão das aspirações de diferentes setores da sociedade envolvidos com os projetos de assistência e proteção social. Nesse sentido, a assistência social que se pretendia realizar, com as leis e ações empreendidas pelo Estado, diferenciava-se da sua ideia original, que segundo Mineiro:

[...] em nosso país como nos demais, originou-se do exercício da caridade, virtude privada, cujo funcionamento era assegurado por associações religiosas ou leigas, cujos recursos provinham das liberalidades dos particulares. Entendia-se que o Estado não tinha a obrigação de assistir aos desgraçados, aos que sofrem de qualquer das múltiplas formas da miséria ou da doença. Atualmente, porém, e já desde algum tempo, está reconhecido e consagrado em leis dos países mais cultos, que é do poder geral do Estado dar uma assistência aos doentes e necessitados, mediante organização administrativa, cuja extensão e aplicação serão determinadas em lei (MINEIRO, 1929, p. III).

Para Beatriz Sofia Mineiro (1929), advogada e assistente do primeiro Juízo Privativo da Capital do país, a assistência social a ser realizada não se confundia com a beneficência privada. Cabia ao Estado o papel de guardião e protetor das crianças, bem como, aos órgãos competentes a manutenção de uma rede de assistência que deveria envolver diferentes modalidades de atendimento. O critério que balizava a realização da lei repousava na sua proposição de conformar os sujeitos ao fim a que a lei se propunha, fosse pelas inclusões e ou exclusões construídas. Firmando-se como uma legislação basilar, o Código procurou instituir uma organização específica 
para a proteção à criança. Além de um abrangente sistema de normalização das ações a serem encaminhadas pela justiça, designou os mecanismos de que o Estado deveria lançar mão para tecer uma rede de assistência de caráter preventivo, punitivo e tutelar, materializada na criação de um movimento de regeneração da infância. Nesse particular, o Código de Menores pode ser compreendido como um regulador das relações sociais, em particular dos setores empobrecidos da sociedade.

Sustentado em uma compreensão da lei como um dispositivo capaz de assegurar a funcionalidade das relações sociais, o Código de Menores foi concebido no contexto de ações de manutenção da ordem e do bem estar social. Ao fixar os critérios de judicialização da infância, o Código pretendeu prescrever e sistematizar os aspectos voltados para a institucionalização da infância e das instituições reafirmadoras de um projeto de nação e de construção de identidades. Assim, antes mesmo de o Decreto n $17943-A$, de 12 de outubro de 1927, ser promulgado, medidas foram implementadas visando instituir efeito, estabelecer diretrizes e determinar as situações e os sujeitos que passariam a "depender" da intervenção do Estado. Este passou a ser concebido como protagonista, como instância tutelar das crianças. Desse modo, em consonância com a reforma judiciária que vinha tramitando no Senado Federal, foi criado o Primeiro Juízo Privativo dos Menores Abandonados e Delinquentes do país, sendo nomeado para o cargo de Primeiro juiz de menores, José Cândido de Albuquerque Mello Mattos. Assim:

[...] A individualidade agora nomeada para a magistratura local é uma daquelas que se impõem à admiração de seus compatriotas, pelos seus altos dotes de espírito e de coração.

Desde cedo o Dr. Mello Mattos ingressou na magistratura. Mal terminara o seu curso jurídico, foi nomeado promotor público da comarca de Queluz, Minas Gerais. Ali pouco se demorou. Era em breve nomeado para idêntico lugar na Capital da República.

O Rio era um campo vasto para o jovem magistrado se expandir. Dotado de um talento superior, de uma solida cultura, com o espírito cheio de entusiasmo, apaixonou-se pela vida agitada do foro, pelo brilho da política (GAZETA DE NOTÍCIAS, 03/02/1924).

Reconhecido por sua atuação no campo do Direito e por suas iniciativas em defesa da infância, Mello Mattos assumiu, a 02 de fevereiro de 1924, o cargo de primeiro Juiz de Menores do país. A matéria publicada pelo jornal Gažeta de Notícias ${ }^{9}$, um dia após a sua nomeação, enfatizava as "qualidades" personificadas na figura do eleito para assumir a judicatura. Com o subtítulo Uma acertada escolha do governo, o jornal apresentava à população carioca, leitora do vespertino, uma biografia que abarcava a sua atuação como Juiz de Direito, advogado criminal, político, professor

\footnotetext{
${ }^{9}$ Outros jornais também seguiram essa orientação, como O Paiz, o Jornal do Brasil.
} 
e benemérito da infância. A sua autoridade e competência advinham da trajetória construída a partir da articulação dos conhecimentos teóricos, acumulados com estudo, formação acadêmica e práticas forjadas no exercício do Direito, da docência e da benemerência aludidas como marcas de distinção.

No entanto, é interessante observar que as qualidades destacadas pela imprensa, a exemplo do excerto de Gazeta de Notícia, não foram atributos "suficientes" para provocar a imediata aprovação do projeto do Código em discussão no Senado. O espaço da política exigiu dele competências próprias ao campo, sendo necessário articular, entre outras iniciativas, uma rede de relações que envolvia senadores simpáticos à questão, entre eles, Mendonça Martins, Silvério Nery, Pereira Lobo, Euzébio de Andrade e Eurípedes de Aguiar. A partir dessa composição o projeto que, com base no Decreto 16.272 de 20 de dezembro de $1923^{10}$, ampliava o campo de atuação dos órgãos já constituídos, criando instituições disciplinares destinadas ao atendimento dos menores delinquentes e abandonados, foi aprovado (O PAIZ, 09/07/1925).

As qualidades enaltecidas pela imprensa foram associadas aos atributos que Mello Mattos defendia como essenciais ao exercício de um juiz. Para ele, o juiz deveria ter uma formação dotada, não somente de conhecimentos jurídicos, mas também, psicológicos, psiquiátricos, pedagógicos e sociológicos. Assim, a justiça que se pretendia corporificar na cidade, com a criação do Juízo e de suas instituições complementares, envolvia a intenção de promover a intervenção no social através de um esforço, não somente em demarcar a infância como território de sua competência, mas também como forma de normalizar as relações sociais por intermédio de medidas protetoras, preservativas e regeneradoras. Desse modo, o Juízo Privativo dos Menores foi organizado como órgão centralizador na elaboração de iniciativas de intervenção, controle disciplinar e normatizador dos assuntos atinentes à infância. Nos dispositivos relativos à competência do juiz, Decreto 16.272, ficava estabelecido entre as atribuições do cargo, o papel de processar, julgar, inquirir, examinar, ordenar, decretar, praticar, impor, fiscalizar e executar todas as medidas necessárias à proteção e assistência ao menor.

Partindo dessa compreensão, Mello Mattos asseverava que a justiça para as crianças não poderia ser feita apenas de direitos, mas também de caridade, indulgência e bondade, uma vez que, era imperioso suprir as suas carências fundamentais. Ao firmar o caráter de caridade às práticas implementadas, o que ocorreu, segundo Camara (2010) foi a transmutação do que deveria caracterizar-se como direito da criança. Desse modo, as ações empreendidas pelo Juiz investiramse fortemente de um caráter assistencial a ponto de ele ser denominado como "o pai das crianças pobres" (REVISTA DA SEMANA, 18/12/1926 apud CAMARA, 2010, p.330). Imbuindo-se dessa

\footnotetext{
${ }^{10}$ Decreto assinado durante a gestão de Arthur Bernardes (1922-1926) e do Ministro da Justiça João Alves, aprovava o Regulamento de Assistência e Proteção aos Menores Abandonados e Delinquentes.
} 
missão e tendo como "bordão de sua judicatura, a máxima cristã, Deixai virem a mim as criancinhas" (CAMARA, 2010), o Juiz Mello Mattos personificou as iniciativas no campo da proteção e assistência à infância, constituindo-se, a partir de então, como referência e padrão a ser seguido pela justiça privativa de "menores", no país.

A aprovação do Código de Menores representou a possibilidade de se firmarem às leis de assistência e proteção à infância, consolidando e prescrevendo medidas premonitórias, pedagógicas e normatizadoras. Nesse sentido, ao longo dos seus 231 artigos, o Código estabeleceu as instâncias legais de intervenção sobre a infância pobre, delimitando o terreno de atuação jurídica e assistencial, bem como as competências dos órgãos e instituições destinados a atuar na "ordenação" das relações sociais. A partir de sua promulgação emergiu a legitimação e conformação de práticas sociais de caráter moralizante, pedagógicas, higiênicas e regeneradoras visando estabelecer um movimento de intervenção tutelar e regulador sobre as famílias. Desse modo,

O Código de Menores ocupar-se-á da Assistência e proteção destes, desde o nascimento até a maioridade, habilitando a autoridade pública a acompanhálos em todas as fases do seu desenvolvimento e educação, amparando-os nas dificuldades da vida acudindo aos maltratados, preservando dos maus contágios os inocentes, arrancando os pervertidos dos vícios e dos crimes $(\mathrm{O}$ PAIZ, 09/07/1925).

De tal modo, importa considerar que em consonância com os debates e embates produzidos no Senado, pela aprovação da Lei, setores da sociedade, a exemplo de jornalistas, juristas e médicos realizavam campanhas e congressos em prol da causa da infância. Nesses eventos, firmou-se, entre suas disposições, a importância em se organizar uma legislação de assistência e proteção à infância para o país. Nessa direção, destacaram-se o Primeiro Congresso Brasileiro de Proteção à Infância e o Congresso Jurídico Comemorativo da Independência do Brasil, ambos realizados por ocasião dos festejos comemorativos do Centenário da Independência do país, no Rio de Janeiro, em 1922. Como assegura Camara (2020), as discussões ocorridas no Primeiro Congresso Brasileiro de Proteção à Infância, no Rio de Janeiro, constituíram-se em terreno propício para a formulação de proposições jurídicas, médicas, educativas, assistenciais e eugênicas, onde:

[...] os intelectuais envolvidos com os debates reclamavam a conveniência em se compor uma legislação, ancorada nas 'modernas' teorias criminal e sociológica, destinada ao atendimento da infância material e moralmente abandonada. Neste tocante, é possível afiançar que premissas foram discutidas e votadas pelos congressistas configurando-se, a partir de 1923, em aportes para as legislações no campo da proteção e da assistência a infância no Brasil (CAMARA, 2020, p. 171-172). 
O clima político, municiado pelas condições em que se encontrava a infância, como também, pelos conflitos sociais e crise econômica do país, dava mostras da importância e da emergência que as questões em torno das medidas protetivas à infância assumiam. Cotidianamente, os jornais noticiavam casos de abandono, de exploração e de maus tratos envolvendo crianças que perambulavam abandonadas pelas ruas da cidade, dando a ver a urgência em se urdirem leis para a infância. Nessa direção, a Revista $A B C$ de 16 de agosto de 1924, afirmava ser urgente definir uma legislação que "[...] de acordo com os modernos criminalistas e sociólogos", criasse "uma jurisdição nova e racional para a infância abandonada e delinquente excluindo o Direito judiciário das tramas do nosso obsoleto Código Penal para um regime de proteção e reforma moral" (REVISTA ABC, 16/08/1924).

A ideia de se instituir uma ação tutelar do Estado ancorava-se no propósito de que era preciso, em situações de abandono das crianças pelas famílias, a atuação esclarecida do Estado como fiel da balança. Assim, a perda do pátrio poder, em decorrência da "impossibilidade ou incapacidade, inclusive financeira, dos pais, permitia que o juiz encaminhasse a criança e o adolescente a instituições de internação" (COUTO; MELO, 1998, p. 30).

Nesses casos, a situação de pobreza, as condições familiares, habitacionais, educacionais, morais e higiênicas, bem como os parcos recursos financeiros e ou desemprego eram agravantes que justificavam a internação compulsória em instituições destinadas à regeneração e ou à proteção da infância. Interessa observar que no ano da criação do Juízo foram internados trezentos e seis menores. Em 1927, esse número chegou a novecentos e vinte e sete menores encaminhados para instituições públicas e privadas da capital do país (GUSMÃO, 1944, p. 14). Em nossa compreensão esses números indiciam a gradual prevalência das medidas jurídicas sobre à sociedade. Sob a órbita da proteção à infância foram elaborados instrumentos legais visando atuar sobre à infância. Assim,

\footnotetext{
A ideia de periculosidade da rua e da família foi amplamente assimilada. Ao mesmo tempo em que sinalizavam para a importância das medidas repressivas contra os que vagavam pelas ruas, indicavam a culpabilidade dos pais e tutores que, por qualquer ato de irresponsabilidade ou de perversidade, colocavam em risco a integridade moral da criança (CAMARA, 2011, p. 31).
}

Todavia, se o Código de Menores determinasse a coercitiva internação de crianças sob o argumento de que o Estado iria promover medidas visando empreender a preservação e ou a regeneração, observa-se que a ideia de inclusão pretendida assentava-se na prerrogativa de que era necessário retirar, das ruas e de suas famílias, as crianças que se encontravam em situação de abandono moral e material, dando-lhes proteção e facultando-lhes a integração na sociedade. Desse modo, interessa-nos pensar sobre os limites e possibilidades do Código de Menores no sentido de 
ter se configurado como uma conquista do direito da infância, mas também como uma forma de o Estado estabelecer a tutela e a regulação das famílias pobres e de seus filhos.

\title{
3. TRABALHO E EDUCAÇÃO COMO ANTÍDOTOS NA REGENERAÇÃO E PROTEÇÃO DA INFÂNCIA
}

Em 20 de março de 1926, o Jornal do Brasil trouxe a lume a triste história do menino Bernardino, de 12 anos de idade, que, preso na Casa de Detenção, "foi brutalmente molestado por vinte presos adultos". Como bem sinaliza Camara (2010, p. 57-58), o caso do engraxate que se rebelou contra um cliente que se recusara a pagar pelo polimento das botinas, evidencia a "degradante situação do sistema prisional", em especial para crianças em decorrência da inexistência de leis protetivas. Nas quatro semanas que passou numa cela com 20 adultos, Bernardino sofreu todo tipo de violência, sendo levado para a enfermaria da Santa Casa da Misericórdia. Para a autora, casos como o de Bernadino são exemplares da forma como a infância trabalhadora era descrita e de como as medidas de interdição dessa infância apareciam como atenuante ao seu sofrimento e exploração. Esclarece Camara (2011) que:

\begin{abstract}
Alternando-se entre estados de pobreza e de completa miséria, a infância desvalida foi compelida à prática da mendicidade, do subemprego, dos pequenos furtos e dos expedientes eventuais e incertos a fim de compor a renda familiar baixa e irregular ou, em algumas situações [...] construir formas alternativas para burlar a carência e a fome. O desemprego, a carestia dos alimentos e dos aluguéis, que caracterizavam a cidade do Rio de janeiro nas décadas de 1910 e 1920, faziam com que, segundo Araujo (1995, p. 49), nas famílias pobres, todos os seus membros trabalhassem, iniciando a criança na luta pela sobrevivência desde tenra idade (CAMARA, 2011, p. 28).
\end{abstract}

Assim o trabalho infantil foi perspectivado como possibilidade de "contribuir" para a sobrevivência das famílias, mas também como antídoto aos malefícios do meio familiar e social decorrente da pobreza. No entanto, as condições de precariedade, de exploração, de insalubridade e de maus-tratos a que estavam submetidas as crianças trabalhadoras, pautaram os debates jurídicos e médicos que prescreviam medidas normativas, higiênicas e preventivas quanto ao trabalho infantil. Para os desvios de ordem moral ou patológica, afirma Gusmão (1944), que eram prescritos "remédios" urgentes, tendo em vista inibir os malefícios que acarretavam "[...] a mortalidade e delinquência infantil que desviam a massa trabalhadora da Nação" (GUSMÃO, 1944, p. 21-22).

Com a promulgação do Código de Menores de 1927, o termo menor passou a ser utilizado como categoria classificatória dessa infância. Deste modo, "menor" passou a significar uma 
situação social do indivíduo com menos de dezoito anos, identificado como delinquente ou abandonado moral ou materialmente. "Sobre ele deveria pairar além da mão protetora e tutelar do Estado, a mão fiscalizadora e vigilante da justiça" na sua preservação ou regeneração (CAMARA, 2010, p. 271).

O poder estatal por meio do aparato legal da justiça passou a regular as relações públicas e privadas no tocante à infância e ao adolescente. Estabelecia-se, então, como assegura Camara (2011, p. 22) a competência das famílias, idealizadas "[...] como objeto de louvor e de crítica social", estabelecendo-se as instâncias destinadas a fiscalizar, vigiar corrigir e regenerar as famílias por meio do Direito da infância. Nessa direção, previa-se que, como crime de desobediência as famílias que se recusassem a "[...] receber a autoridade, encarregada da inspeção ou qualquer pessoa delegada ou autorizada em virtude de lei, é punida com as penas do crime de desobediência, e em caso de injuria ou violência com as do crime de desacato". (CÓDIGO DE MENORES, ART. 4). ${ }^{11}$.

Observa-se que, de acordo com o artigo $4^{\circ}$ aplicava punição à família que se recusasse receber uma autoridade, ou seja, uma pessoa era designada/incumbida para fazer uma inspecção, de acordo com a lei, a fim de punir os familiares que não agissem em conformidade com a lei, incidindo em crime de desobediência, e caso se tratasse de injuria ou violência, era considerado crime de desacato. Assim, esse artigo combinado com a interpretação do artigo 26, V, previa a apreensão do menor pobre que fosse considerado abandonado e que se encontrasse em estado habitual de vadiagem, mendicidade ou libertinagem (CÓDIGO DE MENORES, ART. 26). ${ }^{12}$.

Nota-se, por exemplo, que o termo mendicidade empregado na legislação, permitia o recolhimento da criança pobre como uma espécie de higienização da cidade e domesticação para moralização e subjugação. Assim, cabe inquirir sobre as medidas adotadas que objetivaram proteger e assistir a infância e a adolescência identificadas como menor. Assim, adotando uma nova política social voltada para o ordenamento do espaço urbano e de sua população, previam o "afastamento" dos menores, indivíduos indesejáveis, transformando-os em futuros trabalhadores da nação. Corroborando com essa compreensão, assegura Passeti (2002) que:

Fechavam os 30 primeiros anos da república com um investimento na criança pobre vista como criança potencialmente abandonada e perigosa, a ser atendida pelo Estado. Integrá-la ao mercado de trabalho significava tirá-la da vida delinquencial [...]. Pretendendo domesticar as individualidades e garantindo com isso os preceitos de uma prevenção geral, os governos passaram a investir em educação, sob o controle do Estado (PASSETI, 2002, p. 355).

\footnotetext{
11 O referido artigo aponta que: "A recusa de receber a autoridade, encarregada da inspecção ou qualquer pessoa delegada ou autorizada em virtude de lei, é punida com as penas do crime de desobediencia, e em caso de injuria ou violencia com as do crime de desacato".

${ }^{12} \mathrm{O}$ artigo estabelece que: "Consideram-se abandonados os menores de 18 annos: [...] V, que se encontrem em estado habitual do vadiagem, mendicidade ou libertinagem; [...]".
} 
De tal modo, a internação dos menores em instituições de reforma para as crianças consideradas perigosas e ou de preservação para as consideradas em perigo, indiciava aspectos significativos acerca da compreensão do trabalho. Ora o trabalho era perspectivado como meio educativo, disciplinar e preservativo, ora como medida capaz de regenerar e aperfeiçoar os menores a fim de serem adaptáveis ao trabalho (RIZZINI, 1999, p. 380). No que tange à relação do trabalho e educação, a lei previa medidas disciplinares compatíveis com o sexo do menor. Para meninas destinavam-se as atividades de Costura e trabalhos de agulha; Lavagem de roupa; Engomagem; Cozinha; Manufatura de chapéus; Datilografia; Jardinagem, Horticultura, Pomicultura e criação de aves. Para os meninos, a aprendizagem de um ofício compatível com a idade conforme previsto no $\$ 3^{\circ}$ do artigo 211. Quanto à esse aspecto, Lima (2009) destaca que:

[...] A nova política assistencial do Estado almejava que as instituições asilares funcionassem como uma microssociedade que prevê a adoção de mecanismos de controle, disciplina, educação, trabalho, higiene, e busca inculcar junto aos adolescentes confinados temporariamente ou por tempo fixo, valores morais desejados. As políticas oficiais de intervenção e os saberes assistenciais esclarecidos não diminuíam a pobreza ou seus efeitos e não alteraram a situação concreta dos adolescentes e de suas famílias (LIMA, 2009, p. 90).

Nota-se que era uma prática recorrente a retirada de crianças pobres de suas famílias sob o discurso de dar-lhes melhores condições higiênica, moral e educativa. Essa perspectiva evidencia, não somente uma tentativa de se "domesticar" a criança, mas também de criminalizar as famílias pobres vistas como incapazes e inoperantes. Na discussão dos direitos da criança. Silva (2011) pontua que:

Uma sociedade sã, no sentido moral e físico, implicava o estabelecimento de uma população sem doenças, sem revoltas e sem crimes. Para isso, era necessário eliminar das ruas os vadios, os contagiosos e os degenerados. Antes de estimular a mendicância, era preciso evitar o seu desenvolvimento. Dar uma ocupação através do trabalho, tornando os indivíduos úteis para a sociedade, passava a ser uma preocupação do Estado brasileiro no século XIX. Estado que começava a desenvolver-se economicamente, precisando de homens bons, honestos e trabalhadores (2011, p.2). 
À criança pobre era imposta uma educação para o trabalho. De acordo com Silva (2011), retirar as crianças pobres das ruas, privá-las de suas famílias era identificado como forma de promover a sua proteção. O Código de Menores estabeleceu o trabalho como critério para eximir a criança de ser enquadrada como vadia, estabelecendo a idade e a instrução escolar como requisitos para a sua adoção. Importa destacar que a noção de trabalho próprio ou impróprio foi regulada, restringindo o que seria apropriado à saúde moral e física dos menores. Para Rizzini (2005):

\begin{abstract}
A meta era combater o contingente ocioso da população, enquadrando-o desde a infância à demanda do desenvolvimento capitalista de então, ou seja, transformar a criança pobre em elemento útil para o país. De forma objetiva, era preciso proteger a criança como forma de defesa da própria sociedade. $\mathrm{O}$ discurso apresentava-se, com freqüência, ambíguo, onde a criança precisava ser protegida mas também contida, a fim de que não causasse danos à sociedade. Esta ambigüidade na defesa da criança e da sociedade guarda relação com uma certa percepção de infância, claramente expressa nos documentos da época ora em perigo, ora perigosa. Tais representações não por acaso estavam associadas a determinados estratos sociais, sendo a noção de periculosidade invariavelmente atrelada à infância das classes populares (2005, p. 3).
\end{abstract}

$\mathrm{O}$ argumento de que a criança pobre deveria ser protegida, pautava-se na ideia de que era preciso retirá-la das ruas a fim de dar-lhe melhores condições de vida, considerando-se a rua como uma ameaça. Nessa perspectiva, as crianças que permaneciam nas ruas eram tidas como potencialmente perigosas à sociedade ou em perigo. Às crianças e adolescentes com idade inferior a dezoito anos, o Código de Menores propugnava oferecer educação moral e profissional "adequada" observando-se a "[...] informação do médico, procedência urbana ou rural do menor, sua inclinação, à aprendizagem adquirida anteriormente ao internamento, e ao provável destino" (BRASIL, 1923).

A adequada educação moral defendida associava-se ao que se compreendia ser ou não apropriado ao menor. Cabe informar que, já em Rousseau (1999), as concepções e condutas definida no texto de uma lei representava o interesse de um determinado público da sociedade, ou seja, "Como o arquiteto que, antes de construir um edifício, sonda e examina o solo para ver se pode aguentar o peso necessário, o sábio legislador não começa redigindo leis boas por si mesmas, mas antes examina se o povo a que são destinadas está apto para suportá-las" (1999, p.60).

Nesse particular, conforme o artigo 105, exigia-se um exame de aptidão física do menor, por um médico designado, cujo resultado poderia ser impugnado pelo responsável do menor. Da mesma forma, o artigo 106 previa que as autoridades públicas, responsáveis pela fiscalização do trabalho do menor, também poderiam requisitar o exame dos empregados menores, a fim de garantir que o trabalho prestado não extrapolaria a força física do menor. 
A jornada de trabalho não poderia exceder 6 (seis) horas diárias, o intervalo intrajornada não poderia ser inferior a uma hora, havia também a proibição do trabalho noturno, de acordo com os artigos 108 e 109. A proposta do trabalho “adequado" para o menor visava à prevenção de doenças e uma melhor adequação dos vadios e delinquentes na sociedade, isso porque, de acordo com Marcílio (1989, p. 224), crianças ricas que eram educadas, por conta dos interesses sociais e políticos das elites, para liderar e governar, ou seja, tinham uma educação que as preparavam para os cargos de gestão e administração, enquanto que a criança pobre recebia educação para o trabalho como repressão e moralização. A autor adverte que o primeiro artigo do Código de Menores já previa assistência e proteção à criança considerada abandonada ou delinquente com idade inferior aos dezoito anos. Conforme Marcílio (1989, p.224) a educação prevista no Código para as crianças pobres não era a mesma que recebiam as crianças de classes abastadas.

No entanto, não foi sem críticas que o Código de Menores foi implantado no país e, em particular na cidade do Rio de Janeiro. Segundo Silva (2020), o Código de Menores em seus artigos 117 a 122 objetivava regular o trabalho de menores nas fábricas e nos estabelecimentos industriais, determinando que "[...] os chefes de estabelecimentos industriais que empregassem menores de dezoito anos como operários ou aprendizes eram obrigados a velar pela manutenção dos bons costumes da decência pública, da higiene e segurança dos menores em lugares de trabalho" (2020, p.58).

Em matéria intitulada "Anti-social e absurdo", publicada no jornal A Notícia, de 04 de outubro de 1929, o Código de Menores era apresentado pelos industriais como prejudicial à "normalidade das coisas", dificultando o trabalho dos menores e, nesse aspecto "[...] a ação do Estado é antissocial e, pois, absurda. Contra esse absurdo é que os industriais estão agindo, legitimamente. E o Congresso tem o dever de examinar a questão para corrigir os erros do código imprestável" (A NOTÍCIA, 04/10/1929 - grifo nosso). As criticas formuladas pelos industriais deviam-se, em particular à proibição do trabalho dos menores de 18 anos por mais de 6 horas diárias. ${ }^{13}$, ocasionando em multas para as empresas que desobedecessem a essa lei. Empresários,

\footnotetext{
${ }^{13}$ As normas de direito do trabalho foram inseridas nas constituições brasileiras, a partir da Carta Magna de 1934, que, proibia o trabalho realizado por menores de 14 anos em seu artigo 121, \`1, “d”. A Constituição de 1937 manteve a mesma proibição em seu artigo 138, "k". Em 1943, com a promulgação da CLT, regulamentaram-se normas especiais do trabalho prestado pelo menor. Por outro lado, já na Constituição de 1967, houve um retrocesso, permitindo-se o trabalho do menor a partir dos 12 anos. E, na atual Constituição Federal de 1988, sua redação original, previa como idade mínima para o trabalho 14 anos. Posteriormente, pela Emenda Constitucional no 20, de 1998, deu nova redação para o artigo $7^{\circ}$, inciso XXXIII, no sentido de proibir qualquer trabalho por menores de 16 anos, salvo na condição de aprendiz. Posteriormente no ano de 2000, a lei do aprendiz no 10.097/2000 alterou a redação do artigo 432 da CLT. A jornada de trabalho do aprendiz é de no máximo 6 (seis) horas diárias, ficando vedado a prorrogação e a compensação de jornada, podendo chegar ao limite de 8 (oito) horas diárias, desde que o aprendiz tenha completado o ensino fundamental e se nelas forem computadas as horas destinadas à aprendizagem teórica.
} 
principalmente do Rio de Janeiro e de São Paulo mostravam pelos jornais sua insatisfação fazendo campanhas contra o juiz e o Código. Nessa perspectiva:

\begin{abstract}
Seria absurdo, portanto, que se procurasse encarar a questão do trabalho dos menores nas fábricas por um único aspecto, ou antes, que a pretexto defender regalias para os pequenos operários, se procurasse agredir a classe dos industrias, acusando-a de desumana e sobrecarregando-a de multas e sacrifícios, como já foi feito. Nós somos, por principio, sempre a favor dos fracos, dos pobres, dos homens que arrancam do seu trabalho o pão de cada dia. E somos também a favor dos pequeninos, massa anônima e quase inconsciente que a necessidade muito cedo atira ao campo agro da vida (CORREIO DO BRASIL, 26/08/1929).
\end{abstract}

Para além do trabalho nas indústrias, o Código visou regular o trabalho dos menores de catorze anos e das menores de dezoito anos nas ruas (artigos 112, 114, 116 e 124) das cidades, bem como o trabalho em teatros e cinemas e o doméstico. As medidas que tornaram corpo na lei visavam regular o trabalho abrindo possibilidades para sua realização e manutenção, como a situação dos aprendizes. Em alguns casos, a exemplo do trabalho doméstico, a lei não incidia diretamente na sua regulamentação. Segundo Silva (2020):

O Código de Menores não apresentava artigos específicos relacionados ao trabalho doméstico, mas alguns deles podem ser relacionados. Em seu artigo 104 era proibido aos menores de 18 anos trabalhos extremamente fatigantes e que colocassem em perigo sua vida e saúde. Nos artigos 137 e 141, do capítulo XI do Código de Menores relativos a crimes e contravenções, encontramos punições claras para quem aplicasse castigos, abusos de correção e disciplina a menores de 18 anos, que estivessem sob sua autoridade (2020, p. 75)

Em sua organização, o Código de Menores encontrava-se dividido em duas partes, uma geral e outra especial. Na parte geral, tratava dos objetivos da lei; das crianças da primeira idade; dos expostos; dos abandonados; da inabilitação para o exercício do pátrio poder e a perda da tutela do menor; das medidas aplicáveis aos menores abandonados; dos menores delinquentes; da liberdade vigiada; do trabalho dos menores e da vigilância sobre os Menores dos crimes e das contravenções. $\mathrm{Na}$ parte especial, regulamentava-se o funcionamento do juizado de menores, a competência do juiz para o julgamento dos casos dos menores de dezoito anos e os procedimentos processuais; do abrigo de menores; dos institutos disciplinares e do conselho e assistência e proteção aos menores (BRASIL, 1927).

Incontestavelmente, o artigo $9^{\circ}$, alínea 'a', dava o permissivo legal de retirar a criança do lar com número excessivo de habitantes, ou por ser um ambiente perigoso ou não higiênico. $\mathrm{O}$ mencionado artigo não especificava o que poderia ser considerado um lar perigoso ou o número excessivo de habitantes. Desse modo, como a lei não definia os critérios jurídicos de um lar 
perigoso, não higiênico e com muitos habitantes, tal análise de julgamento ocorreria de forma subjetiva, isto é, caberia diante do magistrado avaliar tais condições para retirar os menores (crianças e adolescentes) de suas famílias, encaminhando-os para internações denominadas colégios internos, profissionalizando-os para uma boa conduta em sociedade de trabalhadores dóceis. A esse respeito, Furlotti (2000) pontua que

[...] as leis em geral no Brasil, por vezes, esse código era 'letra morta', pois os casos em que foi aplicado limitava-se àqueles em que a agressão chegava ao espaço público. O espaço íntimo continuava intocado, a menos que a própria vítima ou outrem que se compadecesse dela denunciasse. Ademais, mesmo os casos julgados dependiam de conceitos subjetivos de juízes e investigadores. (FURLOTTI, 2000, p. 240).

Ao identificarem os menores como ameaça à ordem e à sociedade produziram-se enquadramentos jurídicos e classificados como vadios, abandonados, pervertidos e delinquentes, como observa-se a partir da leitura do artigo 28, do Código de Menores. Nele eram considerados "[...] vadios os menores que: a) vivem em casa dos pais ou tutor ou guarda, porém, se mostram refratários a receber instrução ou entregar-se a trabalho sério e útil, vagando habitualmente pelas ruas e logradouros públicos". Pode-se sustentar que, a partir da análise desse artigo, em qualquer das mencionadas situações, poderia o menor sofrer a interdição do Estado, ou seja, o próprio pai poderia denunciar o filho que não tivesse trabalho útil. A partir de um espectro de adjetivações e classificações estabelecidas na lei, os menores enquadrados nos tipos jurídicos especificados, bem como, suas famílias, poderiam ou deveriam sofrer sanções associadas ao que era considerado impróprio ao seu desenvolvimento moral, intelectual, físico e higiênico. E, assim,

[...] sacrificar a saúde e o direito dos operários menores para proporcionar maiores lucros pecuniários aos seus patrões, e permitir aos pais tirarem dos filhos rendimentos, como se estes fossem propriedade sui generis, que aqueles tivessem o direito de explorar até a custa dos seus perecimentos (LIMA, 2005, p.127).

Nessa direção, a interferência do poder econômico no texto normativo da lei é evidenciada, uma vez que obrigava o menor a prestar serviços sob a pena de responder por vadiagem. O menor abandonado sob a tutela do Estado era encaminhado para escolas (de preservação ou de reforma) a fim de receber educação e instrução para o trabalho. A esse respeito, Vianna (2007) assegura que,

Para os menores moralmente abandonados (não viciosos ou pervertidos), eram indicadas as 'escolas' de prevenção ou preservação, uma para menores do sexo masculino e outra para as do sexo feminino, situadas dentro do perímetro urbano (1906). A eles seria ministrada instrução básica e dedicação ao trabalho, fixado 
em 8 horas diárias. Estas instituições eram também denominadas de 'estabelecimentos industriais'. Via-se com bons olhos o aproveitamento dos menores nas fábricas, como treinamento para o trabalho. O mesmo pode ser dito a respeito na utilização da mão de obra infantil e da juvenil nas zonas rurais, através da criação dos 'Patronatos Agrícolas', destinados aos 'menores abandonados' e à 'mocidade desaparelhada', visando à educação moral, cívica, física e profissional dos menores desvalidos (2007, p.33).

Pode-se dizer que a essência da Legislação era fiscalizar os menores, em especial, as crianças pobres, a fim de "limpar" as ruas da cidade dos indesejáveis e, por conseguinte, dos problemas da criminalidade e da mendicância. No entanto, o menor recolhido e tutelado pelo Estado poderia ser um trabalhador, mas com restrições ao trabalho noturno, jornada de 6 horas e sob a fiscalização de esforço físico de acordo com o exame realizado por um médico, o que prejudicava os interesses dos industriais. O menor considerado delinquente também recebia educação para o trabalho nas instituições destinadas à sua regeneração, conforme Vianna (2007):

Para os menores delinquentes, prescrevia-se a 'Escola de Reforma', localizada na zona suburbana da cidade, que, em 1906, imaginava-se dividida em duas seções, uma industrial destinada aos menores que tivessem sido absolvidos e uma seção agrícola para os condenados. No Rio de Janeiro foram criadas, em 1903, a Colônia Correcional de Dois Rios, com internamento destinado aos jovens desviantes, e a Escola Quinze de Novembro, um instituto preventivocorrecional para crianças entre 9 e 14 anos (2007, p.34).

Destarte, a legislação, com todas as suas falhas e incoerências, representou um avanço no sentido de conferir uma proteção mínima ao menor trabalhador, atenuando as arbitrariedades patronais e lesões à própria saúde, como, por exemplo, a exigência de avaliação física para os menores de dezoito anos, por um médico. Nessa perspectiva, os defensores do Código preceituavam se necessário envidar todos os esforços, empregar todos os meios para a preservação da raça, por conseguinte, da nação.

\section{CONSIDERAÇÕES FINAIS}

Interessou-nos analisar em que medida o Código de Menores, promulgado em 1927 produziu efeitos sociais. Refletir sobre os efeitos provocados por uma lei que perspectivava regular as relações sociais, estabelecendo instâncias fiscalizadoras, coercitivas e disciplinares na sociedade. Pensar o Código significa, em alguma instância, demarcar o seu poder de alcance no sentido de provocar mudanças nas relações familiares e de trabalho no contexto de sua elaboração, mas também pensar o que ele delegou ao futuro como herança. 
No contexto de promulgação do Código de Menores, o crescimento populacional, a urbanização, o crescimento industrial nas grandes cidades e o acirramento da pobreza, intensificaram os debates em torno da infância e à urgência em se construírem políticas públicas voltadas ao combate da criminalidade, da mendicância e do abandono entre os setores empobrecidos da sociedade. A partir do Código de Menores foi possível estabelecer direitos de proteção ao trabalho infantil e outros direitos sociais. No entanto, importa considerar que de algum modo as famílias e as infâncias não se constituíram apenas em objetos passivos dessas medidas jurídicas empreendidas. É possível, a partir da análise das fontes documentais, identificar indícios de resistência, de burla e de apropriação dos termos da lei por esses setores sociais perspectivados como perigosos ou em perigo.

A educação prevista no Código de Menores fomentava o trabalho doméstico para as meninas e a profissionalização para os meninos. Ressalta-se que muita das vezes a internação dos menores fosse na escola, entendida como lugar para os considerados abandonados, ou para os delinquentes, buscava-se promover uma educação voltada ao trabalho e ao interesse dos industriais, a partir de uma mão de obra barata, vigiada e que deveria ser disciplinada, visto que o próprio objeto da lei era para aplicação das crianças em tais condições.

O crescimento da pobreza decorrente do acelerar do desenvolvimento capitalista em marcha, intensificava os problemas sociais, o que exigiu da população pobre a necessidade de criar meios de sobrevivência, que, nem sempre vistos de forma positiva por médicos, higienistas e juristas que os consideravam impróprios. No Código de Menores havia conceitos jurídicos de como tratar o menor vadio, visto como aquele que se recusava a prestar um trabalho útil. A lei, no entanto, não conceituava o que poderia ser enquadrado como trabalho não útil (inútil). Constatamos, assim, que a partir dessa premissa, o julgamento do menor vadio passava por uma análise subjetiva do magistrado. Considerando que era na infância que repoulsava o futuro da Pátria, defendiam que ao preparar "[...] os moços de hoje, estamos preparando os homens de amanhã, sãos de corpo e de espírito, trabalhadores eficientes, cidadãos conscientes de seus deveres, capazes de levantarem alto o símbolo sagrado da Pátria, para a glória do Brasil!" (GUSMÃO, 1944, p. 26). Embora o Código de Menores objetivasse consolidar as leis de assistência e proteção à menores de 18 anos, observa-se que a situação de precariedade, de exploração, de violência e de assujeitamento da infância e, em especial das crianças trabalhadoras, permaneceu como desafio a requerer a produção de medidas capazes de transformar as letras da lei em práticas sociais efetivas.

\section{REFERÊNCIAS}


AGOSTINI, Nilo. SILVA, Luzia Batista de Oliveira. Arte na infância, imagens e memórias: sensibilidades e diálogos formativos. SILVA, Alex Sander da; SILVA, Luzia Batista de Oliveira (Orgs.). Educação, Estética e Experiência: Entres saberes e práticas na contemporaneidade. São Paulo: Editora da Livraria da Física, 2019.

BRASIL. Decreto n ${ }^{\circ}$ 17.943-a de 12 de outubro de 1927 - Consolida as leis de Assistência e Protecção a Menores. Disponível em: <http://www.planalto.gov.br/ccivil_03/decreto/19101929/d17943a.htm> Acesso em 25/03/2021.

BRASIL. Decreto no 16.272 de 20 de dezembro de 1923. Aprova o Regulamento da Assistência e Proteção aos Menores Abandonados e Delinquentes. https://www2.camara.leg.br/legin/fed/decret/1920-1929/decreto-16272-20-dezembro-1923517646-publicacaooriginal-1- Acesso: 29/03/2021.

CAMARA, Sônia. Sob a Guarda da República. A infância menorizada no Rio de Janeiro da década de 1920. Rio de Janeiro: Quartet, 2010.

CAMARA, Sônia. Infância pobre e instituições assistenciais no Brasil republicano. In: FARIA FILHO, Luciano Mendes; ARAÚJO, Vania Carvalho de (Orgs.). História da Educação e da Assistência à infância no Brasil. Vitória: EDUFES, 2011.

CAMARA, Sônia. Celebrar o Brasil, monumentalizar a infância: o Primeiro Congresso Brasileiro de Proteção à Infância e sua perspectiva educativa e regeneradora da criança (1922). In: SANTOS, Maria C. Ferreira; FARIAS, Monica F., RANGEL, Jorge A.; CAMARA, Sônia (orgs.). Intervenções dialógicas: debates sobre educação, ciência e museus. Curitiba: Appris, 2020.

CARVAlHO, Francisco Pereira. Reforma do Código de Menores. Rio de Janeiro: Editor Borsoi, 1970, p.8.

COSTA, Angela Marque da; SCHWARCZ, Lilia Moritz. 1890-1914 - No tempo das certezas. São Paulo: Companhia das Letras, 2000.

COUTO, Inalda Alice Pimentel; MELO, Valéria Galo. Reconstruindo a história do atendimento à infância no Brasil. In: BAZÍLIO, Luiz Cavaliere; EARP, Maria de Lourdes Sá; 
NO-RONHA, Patrícia Anido. Infância tutelada e educação: história, política e legislação. Rio de Janeiro: Ravil, 1998.

NORONHA, Patricia Anido. Infância tutelada e educação: história, política e legislação. Rio de Janeiro: Ravil, 1998.

A NOTÍCIA, 04/10/1929.

DEL PRIORE, Mary (org.). História das crianças no Brasil. São Paulo: Contexto, 1999.

GAZETA DE NOTÍCIAS, 03/02/1924.

GUSMÃO, Saul de. O problema dos Menores. Rio de Janeiro: Imprensa Nacional, 1944.

LIMA, Cezar Bueno. Jovens em conflito com a lei: liberdade assistida e vidas interrompidas. Londrina: EDUEL, 2009.

MARCÍLIO, Maria Luiza. História Social da Criança Abandonada. São Paulo: Hucitec, 1989.

MINEIRO, Beatriz Sofia. Assistencia e Protecção aos Menores Abandonados e Delinquentes. Rio de Janeiro: s/e, 1924.

MINEIRO, Beatriz. Código dos Menores dos Estados Unidos do Brasil - Comentado. São Paulo: Cia editora Nacional, 1929.

NEEDEL, Jeffrey D. Belle Époque Tropical: Sociedade e cultura de elite no Rio de Janeiro na virada do século. São Paulo: Companhia das Letras, 1993.

O PAIZ, 09/07/1925.

PASSETTI, Edson. Crianças carentes e políticas públicas. In: DEL PRIORE, Mary (Org.). História das crianças no Brasil. São Paulo: Contexto, 1999. 
RIZZINI, Irene. A infância perigosa (ou “em perigo de o ser...”): idéias e práticas correntes no Brasil na passagem do século XIX para o XX. Disponível em: $<$ http://www.ciespi.org.br/media/Artigos/Artigos\%20pag\%202/2005_A\%20Inf\%C3\%A2ncia \%20perigosa\%20texto\%20Irene\%20Rizzini.pdf>. Acesso: 26/03/2021.

ROUSSEAU, Jean-Jacques. O Contrato Social. Rio de Janeiro: Ediouro, 1999.

SILVA, Bruna Bottino da. "Em bem dos pequeninos": o trabalho infantil pela imprensa da cidade do Rio de Janeiro de 1924 a 1927. Rio de Janeiro, Universidade do Estado do Rio de Janeiro, Faculdade de Formação de Professores, (Dissertação de Mestrado). 2020.

SILVA, Wandoberto Francisco da. O destino dos filhos pobres, órfãos e enjeitados de Pernambuco: as Companhias de Aprendizes da Marinha (1847-1857). In: Anais do XXVI Simpósio Nacional de História ANPUH. São Paulo, julho 2011. Disponível em: <http://www.snh2011.anpuh.org/resources/anais/14/1296683656_ARQUIVO_TrabalhodoSi mposioNacionalrevisadoIII.pdf.>. Acesso em 28/03/2021.

VIANNA, Guaraci de Campos. Direito - Periódicos. I. Escola da Magistratura do Estado do Rio de Janeiro - EMERJ. Número Especial 2007. Comemorativa do Octogésimo Ano do Código de Menores Mello Mattos. 